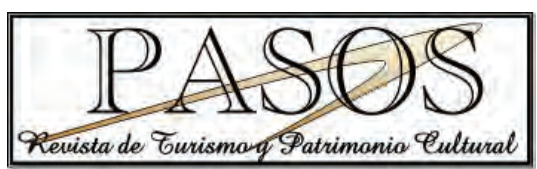

\title{
Una tarde con los auténticos maasai mara. Turismo, autenti- cidad y de cómo eludir un pozo sin fondo
}

\author{
Alfredo Francesch ${ }^{\mathrm{i}}$ \\ Universidad Nacional de Educación a Distancia (España)
}

Resumen: La “autenticidad” es uno de los conceptos clave en materia turística y, recientemente, viene siendo objeto de atención en la literatura especializada. El presente texto trata de eludir un acercamiento demasiado metafísico o esencialista a la autenticidad y propone un análisis en términos de prácticas y producciones sociales. Para ello, sigue un modelo de agencia interactiva en el campo social, conforme al cual los sujetos tratan de hacer valer sus capitales simbólicos. Con este fin, se utiliza material etnográfico recogido en la Reserva Nacional de Maasai Mara (Kenia). El artículo no pretende tanto dar una solución definitiva a esta cuestión, como abrir vías para el análisis más congruentes con las ciencias sociales.

Palabras clave: Turismo; Autenticidad; Valor; Capital simbólico; Maasai.

Title: An Afternoon with the Authentic Maasai Mara. Tourism, Authenticity, and How to Avoid a Bottomless Pit

\begin{abstract}
Authenticity” is a key concept in touristic affaires, and recently it is being attended by specialized journals. This text tries to avoid an overly metaphysical and essentialist approach to authenticity, and it suggests instead of that, analyzing in terms of social practices and productions. It follows an interactive agency model in a social range, wherein people try their symbolic capital to become effective. With this aim, the article envolves ethnographical materials collected on Maasai Mara National Reserve (Kenya). The article doesn't tend to offer a definite conclusion to this mattern, but to open more proper ways to the social sciences.
\end{abstract}

Keywords: Tourism; Authenticity; Value; Symbolic capital; Maasai.

i Doctor en Antropología Social. Departamento de Antropología Social y Cultural. Universidad Nacional de Educación a Distancia (España). Email: afrancesh@fsof.uned.es 
Serviram-me o amor como dobrada fria. (Fernando Pessoa)

\section{Tiempo, lugar, sucesos.}

El momento: mes de julio, en los albores del siglo XXI, aunque bien podría haber sido diez o veinte años atrás. El lugar: un enclave que también puede ser más o menos impreciso, en la Reserva Nacional de Masaai Mara (Kenia) o en sus alrededores, en lo que se denomina "área de conservación". Por acotar algo más: un hotel o un lodge para turistas del primer mundo, prestigioso y frecuente en los itinerarios de viajes organizados, como tantos otros lodges y hoteles prestigiosos y frecuentes en los viajes organizados (hay pocos turistas que elaboren su propio producto turístico en Kenia). El entorno: la planicie de África Oriental que, en esas fechas, surcan decenas de miles de cebras y ñúes, en plena migración, espectacularmente visibles en las estribaciones del altozano sobre el que se levanta el hotel o lodge, prestigioso $\mathrm{y}$ frecuente.

Ya ha anochecido, los huéspedes esperan la hora de la cena en el bar o en el jardín, disfrutando de alguna bebida o curioseando la tienda de recuerdos, después del rutinario gamedrive de la tarde (la excursión para observar fauna que se lleva a cabo entre las 15.00 y las 18.30 , casi rigurosamente, en la práctica totalidad de todos los lodges y hoteles de Masaai Mara). Se relajan de una jornada relativamente fatigosa, que debe sumarse a un buen y fatigoso número de horas y de jornadas previas en un minibús o un todoterreno, dando saltos por la sabana, o por carreteras de asfaltado rudimental, cuando existe el asfalto.

De súbito, un coro terrible de voces rompe la pacífica escena. Son alaridos inquietantes, hirientes, perturbadores, que parecen provenir del corazón de Mordor o de algún otro sitio de pesadilla, pero también son humanos, lo que es casi peor; que parecen provenir de la semilla ancestral de agresividad, violencia y rapiña que, como todo el mundo sabe, perturba nuestra esencia humana con instintos heredados desde lo más profundo del Pleistoceno. La muerte podría esperar a los inocentes turistas, a juzgar por las peculiaridades de esta polifonía infernal, que surge del exterior del jardín y del bar, del exterior de los espacios civilizados. No en vano, sabemos que fuera, más allá de las lindes, más que vulnerables, del prestigioso y frecuente alojamiento, quienes reinan son los leones, los leopardos, las hienas, elefantes, búfalos y otro sinfín de bestias salvajes, en general, y eso cuando no carnívoras, en particular. ¿Por qué no puede haber también humanos acechantes en ese otro lado, humanos no menos salvajes, no menos letales? ¿Por qué no va a darse el caso de que esos predadores humanos masacren a todos los presentes? Como todo el mundo sabe, en este tipo de países ${ }^{1}$ puede pasar cualquier cosa. Ruanda, Liberia, esos nombres del horror, ilustran el peor de los augurios, con sus brazos cortados, con sus pilas de anónimos cadáveres que van flotando río abajo hasta el Lago Victoria, esos trabajos realizados a escala industrial con machetes artesanales. Muerte, tortura, barbarie. El fin.

Pero, la verdad, tampoco hay demasiado tiempo para estas reflexiones (en parte producto del etnógrafo, obligado a autorrepresentarse, para no arrogarse las representaciones de otros). Quién sabe si estas percepciones son percibidas por algún otro, si estos estímulos son experimentados por alguien más, cuando no hay apenas tiempo para la respuesta que caracteriza a todo estímulo. Porque el caso es que, tras el coro horrísono, irrumpen sus intérpretes, en fila india, por el lugar menos esperado. Avanzan a saltos, ora sobre un pie, ora sobre otro, rítmica, acompasadamente, como en un desfile extraño y grotesco. Con la misma cadencia de sus saltos, profieren gruñidos roncos, guturales, secos, cortos, fieros. Visten de rojo, se cargan de ornamentos, portan bastones y también armas, de filo o contundentes, son escurridos de carnes, pero de porte altivo. Son, como era previsible, los masái, o sea, descendientes de gente que, en este caso, vive y ha vivido en Maasai Mara desde hace mucho tiempo. Supongo que por este motivo estas personas son denominadas "los maasai mara" en algún folleto turístico que he podido hojear...

La columna se enrosca sobre sí misma. Los masái forman un semicírculo y su canto comienza: coros rítmicos, una voz solista. Por parejas o individualmente, salen del semicírculo y danzan con profundos saltos, a pies juntos. La técnica no parece fácil, o requiere práctica, al menos, puesto que cualquier remedo que uno intente hacer apenas pasa de lo ridículo, en comparación. Los collares multicolores rebotan sobre el pecho de los varones masái, mientras rebotan en el suelo con asombrosas piernas elásticas. Los turistas crean su propio semicírculo, reflexivo, enfrentado, guarnecido de cámaras, con las que capturan en fotografías y vídeo la escena, para la inmortalidad, o, como mínimo, para la larga longevidad que se supone a los soportes digitales.

Largas melenas rojizas teñidas con ocre denotan a los murrani ${ }^{2}$, a los guerreros. Cráneos rapados denotan a los payiani, los adultos. Es posible ver alguna melena rojiza que es una peluca, lo que no connnota nada claro, pero denota a un guerrero postizo, un touristic moran. En cualquier caso, estas ideales categorías, lo touristic, lo no touristic, que es lo auténtico, se volatili- 
zan en unos instantes. Algunos camareros o cocineros, algún vigilante de seguridad, algún mozo de equipajes, acaban de unirse al semicírculo masái y a los saltos a pies juntos. Si nadie pone cuidado, se capturarán para la posteridad imágenes de guerreros con espadas al cinto, adultos talluditos pero con peluca — aunque también con espadas, por lo menos-y guardias de seguridad o camareros, con su uniforme ambos, de guardias de seguridad o camareros, respectivamente, saltando todos al unísono y en confusión, mezclando irremisiblemente autenticidad - los masái de apariencia masái- y falta de autenticidad - los masái camareros y demás componentes del staff-.

$\mathrm{Al}$ cabo de algún tiempo, difícil de medir en la magia del crepúsculo africano, la formación de los masái recompone la columna que, como vino, se va.

Esa patrulla masái vuelve inmediatamente después. Pero no como columna, sino como individuos aislados. Desde la perspectiva de la meticulosa sociología de Goffman (2001), vuelven los actores de una front region reciclados en personas de una back region. ¿O de una falsa back región que reinicia la representación en una nueva front region? Los turistas conversan con los masái, descendientes de la gente que vive desde hace tiempo en Maasai Mara, y que han representado una danza. Pero, ¿a quiénes quieren tener estos turistas como interlocutores en sus conversaciones? Básicamente, a personasmasái, no a personas no-masái. Por tanto, el actor masái que ahora hable de Kaká y del fútbol europeo, por ejemplo, suele ser interpretado de inmediato como un Otro ("Otro" siempre debe llevar mayúsculas y escribirse en singular, Geertz dixit [2002; 51]) que trata de difuminar de buena fe su alteridad, para laminar las diferencias estereotipadas Yo/Otro, propósito que, de suyo, presupone algo que hay que laminar, y que no puede ser otra cosa que la Alteridad esencial. Si los actores de la front region lo eran en la medida que eran masái, estas personas ahora de la back region siguen siendo masái en la misma medida, aunque ya no sean actores de front region, siguen siendo actores, de algún modo, sólo que ahora de back region, por lo que debemos deducir que la back region es un simulacro y es, sustancialmente, una front region o, como escribía McCannell (1976), se trata de que se ha frontalizado una región trasera.

Por su parte, los turistas no tienen back region que mostrar o simular, aparentemente. Cuando el segundo acto de la representación, el coloquio de los actores con el público, llega a su fin y el espectáculo concluye, los turistas, sencillamente, se retiran a cenar y, algo más tarde, a sus habitaciones. A la mañana siguiente continuarán sus jornadas fatigosas.

\section{Autenticidad.}

Kenia y Tanzania, destinos hermanos en las operaciones de las mayoristas de viajes, proponen en sus circuitos frecuentemente la visita a una aldea masái, que, junto a la representación descrita, componen la oferta "cultural" de un viaje centrado en fotografiar fauna. En buena parte de los casos, lo que se visita son las llamadas cultural villages, que reproducen minuciosamente la distribución, las técnicas de construcción y la apariencia de una aldea cualquiera, pero que no son viviendas habituales ${ }^{3}$. A la vista, la aldea es decididamente auténtica, como lo son los masái — verdaderos masái, no actores disfrazados ni nada similar- que danzan y venden souvenirs. Falta sin embargo el ganado, el transporte de leña y agua, todos los componentes, en fin, de la vida cotidiana. Desde este ángulo, la aldea no es auténtica ${ }^{4}$.

Cuento con algún material etnográfico que expresa juicios sobre este tipo de exhibiciones de cultura masái. Bastan, creo, un par de testimonios:

La visita que te llevan todos los guías a los poblados masái sólo pretenden vender collares, pulseras, etc.. Se visten de gala y adornos, que no llevan en su vida, para que les hagas una foto y te enseñan una escuela con niños que corren a sentarse con sus pizarras dos minutos antes de que tu vayas para hacerles la foto. En esta vida todo se paga, no será menos una foto con los masái.

Tribus masái. Las tribus en sí me parecieron auténticas. Durante los trayectos entre los parques nacionales, ves niños masái, con rebaños de vacas y de cabras, no es un montaje, ellos viven así... Lo que sí me pareció falso es que, en cuanto llegamos al poblado, todos los niños estaban por allí y desaparecieron de repente... Luego lo entendí, se fueron a la escuela...

Al entrar en la escuela, todos los niños nos recibieron con un cordial saludo y uno se levantó y nos hizo una clase de números en ingles y en suahili... En la pizarra había los números escritos en los dos idiomas y la única parte de la pizarra que se veía que había estado borrada una y mil veces, era la de la fecha...

Un niño se levantó y empezó a cantar los números, mientras los demás le seguían a carrerilla. Si los demás no seguían el ritmo, volvía a empezar. O sea, que no sabían los números, si no eran de carrerilla, básicamente porque se lo habrán aprendido a modo de canción; no se si me explico, yo lo comparo con el "a, ante, bajo, cabe, con...,": si no los dices de carrerilla, no te los sabes. Pues lo mismo.

Esto, unido a los cánticos de bienvenida que nos 
hicieron a la llegada, en los que notabas que lo hacían a la fuerza, solo por que antes te habían pedido $50 \$$ para hacer la "visita turística" y tú se los habías dado. Ojo, no me parece mal que se ganen la vida así... Es normal que, viendo pasar cada día cientos de turistas, con cámaras que valen una pasta, teléfonos que valen un riñón, ellos quieran vivir algo mejor. Aun así, esto no quita que me pareciera falso y preparado.

Esta última informante muestra en su expresión de las propias percepciones los malos sentimientos que le producen determinados fenómenos. Los malos sentimientos vienen dados por expresiones como "me parece mal" o "no me parece mal", como lo fundamental de todo este asunto, esto es, términos categoriales con referente moral, "malo"" "bueno". En definitiva, sus experiencias se traducen en representaciones morales negativas. El mal moral no viene dado por los masái, desde luego, ni por el que se "busquen la vida", obviamente, ni siquiera por el hecho de que para ella "buscarse la vida" signifique, con claridad, aspirar a capacidad de intercambio para obtener teléfonos o cámaras. La negatividad moral de su experiencia viene dada por el hecho de que los pastores sean escolares en la infancia y sean ambas cosas a la vez.

La informante entiende de súbito, Saulo turístico en el recinto escolar, que los masái, en sí, como "tribu", no le producen experiencias moralmente desagradables. Entiende que lo moralmente rechazable es que, desde el momento en que los niños masái repiten de carrerilla los números en inglés y en suahili, desde el momento en que ocupan espacios escolares, no deben ocupar espacios como pastores tribales, o viceversa, porque la relación entre ambas posiciones, ambas prácticas, ha de ser, por fuerza, la de una disyunción excluyente. El orden natural de las cosas queda roto con esta ocupación doble, que hace del cosmos un caos. Ante la evidencia empírica de que los niños pastores son también escolares - o viceversa-, este estado de cosas híbrido, generador de caos, recibe una baja evaluación moral ("mal") y un etiquetado de naturaleza a caballo entre lo nominalista y lo esencialista: "no auténtico".

Lo que aquí se dilucida es una cuestión de enorme relevancia en el consumo de turismo cultural. Si los juicios sobre autenticidad se materializan en formulaciones morales, la autenticidad impregna a y se impregna de la totalidad del mundo de la vida de los sujetos. Ahora bien, qué pueda ser la "autenticidad" es asunto que dista mucho de estar claro. Unos pocos ejemplos servirán, por lo menos, en una primera aproximación:

Algunas empresas ofrecen a los turistas viajes a lo largo del río Mahakan, en Kalimantan (la parte indo- nesia de Borneo), a bordo de embarcaciones bien acondicionadas y en las que se disfruta de comodidades muy de agradecer en una zona tan calurosa ${ }^{5}$. Los barcos recalan en algunas comunidades dayak y sus pasajeros presencian esporádicas danzas tradicionales. El autor de estas líneas coincidió una vez en una de estas comunidades con barco, pasajeros y espectáculo, y uno de los turistas, componente de un paquete de origen alemán, receloso, le preguntó si el espectáculo era "auténtico".

En principio, se diría que una danza tradicional no puede tener como motivo para su ejecución la llegada de unos turistas a la localidad. En este sentido, la danza no era auténtica. La técnica de ejecución sí que podía corresponderse con la de una danza practicada por motivos ceremoniales y/o festivos. En este sentido, la danza sí era auténtica. Lo interesante del caso es que, bajo la óptica de este preocupado turista, no sólo la empresa, sino también la comunidad implicada, eran objeto de sospecha en cuanto a la autenticidad del evento. Bajo su perspectiva todos ellos estaban integrados en el cuasi-grupo ${ }^{6}$ turístico y su necesidad de información sólo podía ser cubierta por alguien completamente ajeno a la comunidad danzante y la empresa.

Y no es necesario visitar parajes exóticos para topar con esta difícil combinación de autenticidad y falsificación. Augé (1998: 76) escribe sobre uno de los castillos de Luis II de Baviera:

Luis II ni siquiera vivió ocho días en ese castillo inconcluso: apenas había tenido tiempo para hacer instalar su artefacto favorito [...], apenas había tenido tiempo de llenar aquel lugar de bustos y retratos de los fantasmas que él invitaba a su mesa [...] cuando su trayectoria y su vida se interrumpieron como la construcción de su último refugio. De manera que aquí tenemos el colmo de la copia: no sólo el siglo XIX imita al XVII, sino que el castillo es una ficción de castillo.

Un antiguo catálogo de Halcón (Primavera-Verano 2002) propone para otro de los castillos de Luis II una curiosa anacronía, que revela los complejos mecanismos de la autenticidad. El sello de garantía, el marcador que identifica el enclave como tal, vendría dado por el hecho de que el castillo resulta haber "servido de modelo a W. Disney para el suyo de la "Bella Durmiente»". El castillo de Disney, conforme a este planteamiento, no queda legitimado por imitar el de Luis II, sino que éste recibe el sello de garantía de manos de Disney. Si el castillo de La Bella Durmiente se hubiera inspirado en, digamos, el de Manzanares del Real, en La Mancha española, el castillo bávaro carecería de interés turístico, dentro de esta lógica.

Un informante me describe sus sensaciones durante 
la visita a un campo de trabajo de elefantes de Tailandia:

A mí me da la sensación de que esos elefantes algún día curraron [...]. Hicieron un espectáculo que..., bueno..., llegaron a jugar al fútbol los elefantes, tirando penaltis. Luego, sí, arrastraban troncos, cargaban troncos. Hacían un poco la demostración de lo que había sido el trabajo de los elefantes, pero vamos, se notaba que era para turistas, no era una explotación de nada.

Lo "no auténtico" es hybris, es lo que rompe un orden armónico ínsito en las cosas por la propia naturaleza de esas cosas, un orden que les es inmanente. El viaje contiene y en él se buscan múltiples experiencias, por descontado, pero lo que con toda seguridad no se busca en viaje alguno es lo no auténtico. Pone esto en claro el que una auténtica falsificación sea, con certeza, moralmente válida. La Polinesia de Port Aventura o la libertad de los leones de un Safari Park no son "auténticas" polinesias o libertades, y sólo alguien definitivamente despistado podría confundirse al respecto. Son auténticas falsificaciones, y eso es lo que se espera de tales enclaves.

De hecho, la falsedad es tan auténtica que se ha dado el caso de unos turistas que, malinterpretando esas condiciones de auténtica falsedad, han entendido que los tigres de un recinto de este tipo estaban impregnados de la misma condición de simulacro que el recinto en su conjunto, sufriendo por imprudencia el auténtico ataque de auténticos tigres y muriendo a resultas de un error en la descodificación ${ }^{7}$. La autenticidad de la falsificación falsifica suficientemente la autenticidad como para crear verdadera confusión en el manejo de los contenidos semánticos y pragmáticos. Pero lo que pone muy claro el aciago error de esa pareja de turistas es que había algo auténtico en ese recinto, aunque sólo fuera la falsificación.

En el mismo sentido, aunque con consecuencias menos nefastas, podemos encontrar el caso del turista agredido por los indios provenientes de reservas que, en Port Aventura, realizan rituales y se sintieron ofendidos por el comportamiento de este visitante, que al parecer, componía muecas y otros gestos burlones (Rodríguez Regueira, 2000). La intensión de los elementos auténticamente falseados es lo suficientemente perceptible para cualquiera, pero, tal vez por ello, la extensión de falsedad y autenticidad no es nítida y los receptores de estos complejos mensajes pueden perderse en un dédalo sémico.

Las cosas van más allá de las prácticas turísticas. Como se ha repetido hasta la saciedad en las últimas décadas, las prácticas turísticas remiten en último tér- mino a los mundos de la vida cotidianos, a la existencia profana, complementaria y antagónica a las sagradas vacaciones, ese tiempo de la turistidad ${ }^{8}$. Por ello, las experiencias del viaje se traducen en categorías universalistas y universalizantes, que tratan de coordinar, complementar, fusionar, tiempo de vacaciones, de viaje, de turismo, espacios desconocidos, con tiempos conocidos, sedentarios, laborales, y espacios habituales.

En la expresión y la conducta, en el discurso y la praxis, esta flexión, esta conjugación de lo excepcional y lo usual, sólo puede realizarse acudiendo a planteamientos, como ya he dicho, universalizantes y universalistas: ahí es donde cobra cuerpo lo moral, representación paradigmática y objetivada de lo universalizante y lo universalista. En la autenticidad, confluyen las valoraciones generales del viaje en sí, porque es condición necesaria para la cualificación moral del viaje, pero también porque la autenticidad no es sólo un atributo deseable de las actividades turísticas, sino un atributo deseable, moralmente bueno, de la vida. La propiedad de ser o no auténtico, en viajes y en turismo, pero también en personas, acciones, condiciones, entidades, objetos, cosas, situaciones, del tipo que fueren, se instala en campos de mayor relevancia y mayor profundidad que lo turístico. Se vincula a lo más profundo y más arraigado de lo cultural.

\section{El campo social.}

La base de esta afirmación un conjunto de reflexiones recientes sobre la autenticidad que mantienen como advocación última la metafísica de más alto calado. Podemos ver como una serie de autores citan a Kant, Hegel o Heidegger como recursos útiles para desentrañar las complejidades de la autenticidad ${ }^{9}$. Cuando la autenticidad, a partir de los sucesos y los estados de cosas que se dan entre los turistas, puede concluir en la más profunda filosofía de la existencia, es que mis hipótesis no están del todo desencaminadas. Por todo ello, el concepto de "autenticidad" merece un detenimiento cuidadoso y de carácter analítico dentro de un marco de investigación social poco tendente a la especulación. A mi juicio, afirmaciones sobre todo este asunto como la que sigue, suscrita por Baudrillard (2002:40) en su tratamiento de la aparente confusión entre lo "auténtico" y el simulacro, carecen de interés en la investigación social:

Un atentado en Italia, por ejemplo, ¿es obra de la extrema izquierda, provocación de la extrema derecha o un montaje centrista para desprestigiar los extremos terroristas y reafirmarse en el poder?, más aún, ¿se trata de una farsa policíaca, de un chantaje a la seguridad pública? Todo ello 
es verdadero al mismo tiempo y la búsqueda de pruebas, es decir, de la objetividad de los hechos, no es capaz de detener semejante vértigo interpretativo.

Es posible que un intento de determinar al agente causal de tan esotérico atentado propicie este "vértigo interpretativo". Pero el analista no debe confundir un estado de cosas o un suceso con las expresiones lingüísticas plurales que se generan acerca de él. El auténtico agente causal —en el sentido aristotélico de "causa eficiente"- puede ser la extrema izquierda, la extrema derecha, el centro, la policía o una cadena de televisión que busque ampliar su audiencia, eso no nos importa. Lo que sí importa es que rematar este análisis - llamémosle así- con la expresión "todo ello es verdadero al mismo tiempo" es verdaderamente desafortunado y sólo consigue aumentar la confusión. Acaso la solución del enigma esté en que el autor del atentado haya sido el propio Baudrillard...

Cuando Reisinger y Steiner (2006) escriben: "para explorar conceptualmente la autenticidad existencial se necesita disponer de un sentido de lo que significa ser humano"; o Berger (1973), citado por Wang, propone que: "en términos de sentido común, la autenticidad existencial denota un estado especial del Ser en el cual uno se es verdadero a sí mismo, y que actúa como contrapartida a la pérdida del verdadero sí en la esfera y los roles públicos", no hemos avanzado mucho, sospecho, tratando de comprender el turismo como cosa social - conforme hubiera querido Durkheim. Desde mi punto de vista, esta cuestión de los turistas no gana en comprensión si para ello tenemos que irnos hasta los estados especiales del Ser o el significado del ser humano.

Por lo demás, apeándonos de las incursiones en la ontología, no ha de pensarse que la autenticidad sea una preocupación exclusiva del turista. Instituciones como ICOMOS, International Council of Monuments and Sites, o la UNESCO vienen a ser sistemas expertos en la gestión del valor "autenticidad". Esto puede comprobarse mediante el sencillo expediente de revisar la documentación de estos organismos, entre la que puede, por ejemplo, encontrarse The Nara Document on Authenticity, redactado en el Congreso de Nara (Japón) en 1994, con participación de instancias japonesas, las dos instituciones citadas, así como ICCROM, International Centre for the Study of the Preservation and Restauration of Cultural Property. El documento de Nara asume lo complejo de medir la autenticidad: deben evitarse formulas mecánicas o procedimientos estandarizados, debe involucrar colaboración multidisciplinar y usar todo el conocimiento accesible, atender a valores y circunstancias cambiantes, etc. UNESCO,
ICCROM, ICOMOS, son instituciones que certifican el rico patrimonio de determinados enclaves. En el aludido documento de Nara se encuentran declaraciones tan contundentes como: "la autenticidad [...] se revela como el factor esencial de cualificación en lo que concierne a la valoración" [del patrimonio].

Frente a estas garantías institucionales, enclaves turísticos de menor valor patrimonial y de "autenticidad" menos prestigiosa introducen en escena a protagonistas también de menor rango. Por ejemplo, algunos paisajes en circuitos por Túnez ponen en marcha comentarios del guía, que informa al grupo de que sus especiales características los hicieron merecedores de ser elegidos para localizaciones en películas como El paciente inglés o ciertos episodios de la saga La Guerra de las Galaxias. Las garantías aquí son presentadas por agentes de rango menor. Los especialistas en la búsqueda de localizaciones o los críticos de cine que hagan mención de la belleza de los paisajes certifican patrimonio, pero no cuentan con la autoridad de sistemas expertos internacionales, aunque el turista no quede del todo abandonado a su propio criterio a la hora de juzgar.

Del mismo modo podríamos hablar de antropólogos juzgando una ceremonia, arqueólogos juzgando ruinas, críticos de gastronomía juzgado alimentos, o, como ocurre habitualmente, de autores de guías turísticas para un buen sinfín de enclaves. Es decir, se trata de agentes que no producen patrimonio, sino que disponen de saber experto y reconocimiento social sobre elementos que, estos sí, son integrables en un producto dado. Arqueólogos, gastrónomos, historiadores del arte o etnólogos son en principio ajenos a lo turístico, pero sus producciones intelectuales sí pueden ser absorbidas por los sistemas expertos turísticos, que, al incluir determinados componentes en su producto, los certifican por medio del placet de estos agentes especializados; ellos son quienes dan su visto bueno a tales ruinas, tal comida típica, tal procesión religiosa. En cualquier caso, no veo forzoso mostrar más casos, que el lector puede encontrar a voluntad fácilmente. Lo relevante aquí es que contamos con una escala en rangos de actividades, paisajes, monumentos, etc. en cuanto a autenticidad y valor y una escala paralela de garantes o avalistas.

Los restantes enclaves y actividades son las ya señaladas danzas para turistas, elefantes futbolistas, etc. Aquí nadie certifica ni garantiza valor alguno. El turista es el único que puede enjuiciar si estas visitas, si estos enclaves, si estas actividades le enriquecerán o no ${ }^{10}$. El turista, en territorio ajeno, tal vez en ámbitos culturales muy distintos, acaba preguntando, según se ha visto, si unas danzas son auténticas al primero que aparezca por ahí y no tenga aspecto de estar rela- 
cionado con el entramado turístico. Abandonado a sus recursos, ha de juzgar por sí mismo. La cosa se enreda aun más, teniendo en cuenta que "autenticidad" y valor patrimonial se funden en una mezcla difícil de separar. La "autenticidad", en principio, parece ser requisito imprescindible para el valor patrimonial, pero aunque sea condición necesaria, puede no ser suficiente. Si, para continuar con el ejemplo del circuito tunecino, el grupo, en su periplo por el desierto, arriba a un decorado que se empleó durante el rodaje de La amenaza fantasma, enclave auténtico, el de verdad, el verdadero decorado de la película verdadera, ¿cuál es su valor? En cualquier caso, conforme a la lógica propia del turismo, los turistas se corresponden con el enjuiciamiento de ítems de mínima autenticidad y mínimo valor patrimonial, que juzgarán con toda probabilidad como tales. Estos enclaves exclusivamente turísticos son fuertemente enclasantes, dado que sitúan a los turistas en el último rango jerárquico.

Paralelamente, este planteamiento nos sitúa ante otra cuestión de relieve, como es la de la confianza. Mediante un mecanismo circular, los agentes de alto rango legitiman enclaves de alto rango en la medida en que existe confianza en su competencia para ello, al tiempo que esos enclaves sólo pueden ser legitimados por esos agentes. Los agentes especializados cuentan con capacidad para poner candidatos en las listas de ítems de máximo rango (arte de vanguardia, actividades poco conocidas, etc.), o dar garantías para valores medios. Que sean tales agentes y no otros, en los papeles que les son pertinentes y no otros, es a la vez causa y efecto de una confianza social consensuada en que son los adecuados y realizarán correctamente su cometido ${ }^{11}$.

Para penetrar en todo este enmarañado territorio, creo posible partir del principio de que la autenticidad, por sí, es valiosa. Eludiré las esencialistas y siempre alambicadas reflexiones sobre lo que es en sí valioso o deja de serlo, para tratar de centrarme en la forma que el valor adquiere en la acción social, que, en tanto que antropólogo, es lo que -intuyo-debería orientar la reflexión, con el respeto debido a Heidegger y demás pensadores. Si propongo este tipo de aproximación, es porque rastrear las intensiones de la "autenticidad" en tanto que "valor", bien lejos de suponer un trabajo analítico, supone una inmersión completa en el mundo de la vida de los sujetos cuyo mundo de la vida uno pretende, precisamente, analizar, supone asumirlo como el mundo de la vida. Dicho de otro modo, analizar la "autenticidad" por cuanto es un "valor", investigando qué pueda ser esa "autenticidad" en sí, qué pueda ser esa autenticidad en la medida que es un "valor", y qué pueda ser un "valor" en sí, no es exactamente profundizar. Es más bien caer en un pozo sin fondo.

En pocas palabras, trataré de seguir un hilo que parte de la sencilla proposición de que lo valioso es lo que se hace valer. Para ello, utilizaré el mapa propuesto por Díaz de Rada (2007), conforme al cual, cuando algo se hace valer, o sea, es valioso, ha de buscarse en el análisis, por lo menos, a) un cardinal lo más discreto posible de elementos activos en un campo de acción concreto; b) la delimitación de ese campo de acción social; y, a partir de ahí, la localización de las posiciones de los agentes en ese mismo campo y sus vinculaciones entre sí; y c) perfilar sus dimensiones semiótica y paramétrica, esta última en términos de capitales posibles y pasibles de ser puestos en juego en la acción social. Conforme a este modelo, propongo que un análisis de la "autenticidad", en tanto que representación de un "valor" para el agente cuando es turista y cuando no lo es, no se debe examinar rastreando las confusas y difusas intensiones del término, ni los atributos de la característica "auténtico", predicativa de cualquier sujeto gramatical imaginable, sino que debe analizarse en campos de acción social, en los que se dan diferenciales de poder pragmático, cargados de expresión simbólica.

Contamos, pues, con un ejercicio social, consistente en la asignación de una entidad simbólica de naturaleza comparativa, la "autenticidad", a muy diversas entidades, entre las que se establece una relación de coincidencia y otra de precedencia, en función de criterios propios del agente. Contamos también con una serie de agentes que van desde sistemas expertos internacionales a turistas anónimos. Lo ingente en el cardinal de sujetos impide manifiestamente establecer sus dimensiones posicionales y sus vínculos en el campo social, por lo que habremos de soslayar este paso, al alcance del investigador en un campo delimitado más estrictamente y de proporciones algo más manejables ${ }^{12}$.

Las diferencias entre estos sujetos se expresan, en el campo que nos ocupa, por medio de operaciones semióticas ("formas de habla, vestuario, formas corporales, emblemas étnicos, políticos, religiosos, etcétera" [Díaz de Rada, op. cit.]). En el uso de esas operaciones semióticas se revela una segunda dimensión ya paramétrica: un capital que arroja sobre el campo crudas relaciones de poder, al cobrar cuerpo en forma de diferenciales perceptibles entre unos sujetos y otros. Este capital, que en otras situaciones podría materializarse, por ejemplo, sencillamente en dinero, se configura aquí en términos de lo que llamó en su día Bourdieu (1988) "capital cultural”. La expresión, sin embargo, parece poco aconsejable en la disciplina antropológica, en la que el vocablo "cultura" desborda el conjunto de saberes al que refiere Bourdieu. Denominarlo "capital escolar", como en la 
propuesta de Díaz de Rada, es impreciso en este caso. Hay saberes tradicionalmente no escolares que aquí entran en liza, como los que mencionamos al hablar de gastronomía o, por ejemplo, los adecuados a espectáculos turísticos que no lo son en exclusiva, como corridas de toros ${ }^{13}$. A falta de términos mejores, y con el único propósito de poner nombre a las cosas, sin mayor aspiración, utilizaré la expresión, que reconozco un tanto engorrosa, "capital en saberes".

A la vista de lo expuesto, no es difícil correlacionar las escalas de rango de los distintos agentes con distintas formas de capital en saberes y con las jerarquizaciones en valor de los enclaves y las actividades turístiscas. Así, los estratos superiores de enclaves y actividades encontrarían correspondencia con las formas de capital en saberes más institucionalizadas, más certificadas y de más difícil rechazo. Monumentos de la Atenas de Pericles, formaciones geológicas, rutas históricas, son perfectamente acoplables a las categorizaciones y clasificaciones académicas, son los ejemplares ilustrativos de los libros de texto, forman parte de la cultura escolar más innegable, salvo heterodoxia. Los agentes facultados para dotar de atribuciones en valor son los vinculados a los sistemas expertos, en cuya cúspide se situaría la UNESCO, por cuyas certificaciones existen auténticos concursos internacionales. Según se va descendiendo en rango, el capital requerido para enjuiciar es de índole menos institucional. Nuestro decorado cinematográfico o una corrida de toros exigen la puesta en juego de otro tipo de saberes, menos fáciles de certificar con títulos, producto de una trayectoria vital y de la costumbre de enjuiciar de manera más libre, con arreglo a criterios más personales y a un gusto construido (es decir, algo más propio de artistas o intelectuales que de sistemas expertos). En el último rango de la escala estaría la retirada de la escena del capital escolar como elemento actuante y también del capital en saberes, en sus formas más autónomas. Es decir, que estas correlaciones arrojan un cuadro como el siguiente:
Encuentro dos aspectos fundamentales en este cuadro. Cuando un especialista en arte prerrománico realiza una visita turística a un templo prerrománico, el capital en saberes que pone en juego es extremadamente reducido, si no nulo, en la medida en que, en esa condición, no cuenta con la más mínima posibilidad de modificar el status del templo en las jerarquías de valor. Su capacidad, sin embargo, sí entraría en acción desde su despacho en una institución que velara por el patrimonio histórico-artístico de la zona, pongamos por caso. Consecuentemente, aunque la fila intermedia del cuadro ofrece amplios espacios de maniobra y caben casi todos los ejemplares imaginables de cualquier dominio, el sistema es notablemente rígido. Si el turista enjuicia valor o autenticidad en tal o cual actividad o enclave, su acto de valoración no lo encuadrará en el papel de "agente especializado", ni tan sólo de forma interina, provisional. Durante el enjuiciamiento, la tasación, hace uso de sus saberes pero de manera ilegítima: su condición de turista no le permite ejercer acción en el campo desde otra posición. Un agente humano no puede ocupar a un tiempo dos posiciones. Ejercer facultades para la atribución de valor es aquí una práctica "profesional" y, cuando turista, el agente ocupa posiciones ajenas a lo profesional, se trate de quien se trate.

En segundo lugar, conviene hacer hincapié en que no nos hemos limitado a centrarnos en la categoría nativa de lo "auténtico", sino que hemos aumentado la escala del mapa y adquirido una perspectiva más amplia, lo que hace posible ver conexiones de dominios que exceden lo meramente turístico. Es decir, el cuadro sintetiza la estructura de ciertos dominios mediante un corte transversal, y esos dominios y su estructura forman parte del imaginario social, del repertorio de representaciones por el cual los sujetos se apropian de y operan con su mundo de la vida, haciendo turismo o no. El cuadro no recoge estructuras categoriales exclusivas del consumo turístico, sino que pone éstas en conexión con representaciones ordinarias del mundo de la vida. La

\begin{tabular}{|l|l|l|}
\hline $\begin{array}{l}\text { VALOR/ } \\
\text { AUTENTICIDAD }\end{array}$ & $\begin{array}{l}\text { GARANTES/ } \\
\text { POSICIONES }\end{array}$ & CAPITAL EN SABERES \\
\hline Máximo & Sist. expertos de alto rango & Institucional \\
\hline Variable & Agentes especializados & $\begin{array}{l}\text { No necesariamente } \\
\text { institucional }\end{array}$ \\
\hline Mínimo/Nulo & Turistas & Ninguno \\
\hline
\end{tabular}


actividad del turista se realiza en un marco cognitivo que es, de antemano, familiar, en el que las relaciones entre capital de saberes, agentes garantes y atribuciones de valor son previas al consumo del producto turístico. La organización de este campo es experimentable desde antes de emprender viaje alguno. El viaje testa la validez de este conjunto de relaciones, de esta estructura, al incorporarle como ejemplar, como estudio de caso, un enclave o una actividad concreta.

Las características de este sistema no permiten que la incorporación de un nuevo ejemplar altere la configuración previa. Es fácilmente perceptible la jerarquía operante en la vida ordinaria. Llegado el momento de consumir el producto turístico, surge ese nuevo caso, ese nuevo ejemplar, que es acoplado al esquema previo, recibiendo en ese mismo momento un orden. Al acoplarse a una organización sistémica del tiempo ordinario ya existente, la configuración que adoptará en su ajuste es necesaria, forzosa, inevitable. Alterar el orden de cualquiera de las filas o columnas del cuadro presentado nos llevaría a una organización absurda, inverosímil.

\section{Conclusión}

Establecido así el marco analítico, la imagen de los turistas, de los danzantes masáis y las suspicacias de los primeros reciben nueva iluminación y se perfilan con mayor nitidez.

No existe - o, al menos, yo no encuentro - un motivo razonable para poner en duda la "autenticidad" del espectáculo, desde una categorización nativa de lo "auténtico". Sus artífices son masái, cien por cien masáis, con arreglo al imaginario de lo que debe ser un "auténtico masái”. Cierto que utilizan teléfonos móviles, compran vacunas para su ganado o reciben salarios por trabajos; pero, en su mayoría, vivirán en manyatas en las cercanías, no en edificios de apartamentos, en adosados, en rascacielos. En su mayoría, serán propietarios de una cabaña ganadera más grande o más pequeña, detalle trivial en este momento. En su mayoría, habrán pasado por la secuencia de pasajes ritualizados que sea propia de su grado de edad. El baile ejecutado habrá sido un baile perfectamente normal, no una nueva y sensacional coreografía creada ad hoc. ¿Cuál puede ser el problema que conduzca a la inautenticidad (pragmática, que no del Ser)?

Evidentemente, los turistas no han llegado a una aldea en el momento justo en el que, por cualquier motivo, los pobladores se disponían a emprender bailes por iniciativa propia. Dado que los turistas no pueden visitar a los masái a su antojo, son los masáis los que les visitan a ellos, por expresarlo así. Y este hecho podría ser el que ponga a los turistas en condiciones de valorar con muchas precauciones y muchos reparos danza y danzantes. Pero esta regla para atribuir valor, "autenticidad", no parece estar clara, ni mucho menos. A la postre, nadie alberga sospechas - yo, por lo menos, nunca las he escuchado de labios de turista alguno- sobre la "autenticidad" de Nôtre-Dame, aunque esté siempre llena de turistas, en lugar de estar llena de clérigos y de devotos cristianos orando, bautizándose, o lo que fuere. La "autenticidad" y sus reglas de atribución son absolutamente incomprensibles empleando las prácticas nativas, por mucha racionalización que se ponga en ello. Que lo más visible sea la presencia de los turistas no es un rango necesario para lo "falso", como podría parecer. El llamado "efecto Heisenberg" es operativo unas veces sí y otras, no, en este universo. La presencia de turistas no "falsea" la atracción turística, aunque así lo expresen los sujetos hasta la saturación.

La "autentidad", en definitiva, es una entidad simbólica sobre la que se produce acción social en términos de "valor", es decir, moral, y que los agentes hacen valer para situarse en posiciones de poder variable, dentro de un campo sistematizado y notablemente rígido, posiciones dotadas de la suficiente capacidad semiótica como para hacer inteligible la capacidad agencial —o su carencia- de operar en el campo en liza. Las diversas magnitudes de capital en saberes son los elementos simbólicos que suministran a esos agentes la legitimidad para repartir atribuciones de "valor", conforme a reglas. Una de esas reglas es que las atribuciones deben llevarse a cabo de manera estrictamente profesional. El "valor", pues, es una atribución que sólo puede asignarse legítimamente cuando se hace a cambio de retribución por el trabajo de asignarla.

$\mathrm{Al}$ expresar y experimentar dudas sobre la "autenticidad" de la escena en el hotel, los turistas ponen de relieve sus conocimientos sobre el sistema de atribuciones de valor, sobre el campo en que maniobran. Saben, y hacen saber que lo saben, que en este campo concreto su posición no les permite atribuir valor a las cosas, por lo cual las cosas pendientes de valorar que se les ofrecen ni serán, con toda probabilidad, valiosas, pues ya habrían sido certificadas por los agentes adecuados, ni deben recibir atribuciones por su parte, puesto que no es ese su papel.

Un imaginario etnógrafo, imaginemos, que formara parte del grupo de turistas y les informara de que todos esos danzantes son vecinos de la zona, pastores, etc., podría ser escuchado y atendido, pero su discurso sobre la "autenticidad" carecería de eficacia (en medida variable, claro), dada su condición de turista. Podría ser neutralizado por todos esos teléfonos móviles o cualquier otro 
elemento perturbador, que arrojaría sombras sobre el valor de "autenticidad" propuesto. Sin embargo, si ese mismo etnógrafo no formara parte del grupo de turistas, pero se encontrara allí en el mismo momento, por cualquier motivo, durante un trabajo de campo en la zona, su discurso sí sería acción efectiva en el campo social (también en medida variable, como es lógico) ${ }^{14}$.

El campo, he propuesto, es bastante rígido. Consecuentemente, no está exento de pugnas, como cabe esperar. Puesto que en él se dan relaciones de poder trabadas mediante operaciones simbólicas, los agentes tratan de ocupar posiciones prestigiosas o de deslegitimar las ya prestigiadas y ocupadas. Los agentes especializados y en disposición de utilizar un capital en saberes tratan de prestigiar sus posiciones frente a los sistemas expertos, atribuyendo valores a nuevas actividades o a nuevos enclaves, o intentando subvertir las atribuciones canónicas. Los turistas, por su parte, situados en la base de este sistema, claramente enclasante, no disponen apenas de márgenes de maniobra, por lo que oscilan entre la adhesión a unos u otros agentes, en función de la actividad que realicen o del enclave que visiten. Desde el momento en que se opta por este tipo de producto turístico de manera voluntaria, se pone de manifiesto que el turista quiere, o, como mínimo, acepta, participar en las maniobras de poder y de oposición, de operaciones simbólicas y de acción en el campo. Pondrá entonces de manifiesto su destreza atribuyendo "inautenticidad" a cuanto encuentre sin certificar, y dando su aquiescencia a las certificaciones producidas por unos u otros agentes. Por supuesto, es posible la existencia de algún turista que no tenga el menor interés en participar de las maniobras de toma de posición en este campo, pero entonces lo más probable es que se vaya a una playa o a hacer cualquier otro tipo de cosa.

Obviamente, aunque en este campo de acción social la condición de turista es la más desprovista de prestigio, dentro de su propia posición existen jerarquías. Se diría que un turista diestro en la gestión de atribuciones de valor ocupa mejores rangos que otro que, pongamos por caso, mostrara reticencias ante Nôtre-Dame y un gran entusiasmo por los elefantes futbolistas, quien más bien daría la sensación de actuar a tontas y a locas (salvo que se tratara de alguna especie de artista excéntrico, o algo parecido). En la cúspide de la jerarquía turística, algunos turistas, bien por su capital en saberes, bien por su experiencia en viajes (o ambas cosas a la vez), intentan acceder a la posición de agentes especializados, pero, con independencia de que los asistentes a su esfuerzo lo puedan admitir, la realidad es que sólo la actividad profesional ejerce acción en el campo. Un viajero incansable que convenciera a un editor y escribiera una guía turística, por poner un caso, sí habría comenzado a ejercer acciones efectivas y no remedos, tentativas. Con todo, estas estrategias, estas tácticas, el conjunto de acciones posibles del que hagan uso los agentes para alterar sus posiciones, no implican en absoluto que las posiciones en sí experimenten modificaciones, sino todo lo contrario. Las pugnas simbólicamente configuradas por ocupar posiciones de poder, o por dotar de poder a las posiciones ya ocupadas, más bien ponen de manifiesto el hecho de que esas posiciones y la jerarquía que las vertebra son enormemente sólidas y reacias a las transformaciones. Posiblemente, un campo más flexible o más hospitalario a nuevas posiciones atenuaría el cardinal y la aspereza de los conflictos.

Adicionalmente, ocurre que la rigidez de esas posiciones es la que legitima moralmente las tentativas de cambio de posición de los agentes que así se comportan, por cuanto no hay nada más natural en un ser humano que querer incrementar su propio prestigio, con independencia de la forma cultural concreta que adopte el prestigio. El imaginado etnógrafo que formaba parte del grupo de turistas y trataba de informarles sobre la "autenticidad" masái, que hemos propuesto líneas atrás, probablemente sería atendido, decíamos. Y sería atendido porque, por un lado, el grupo de turistas admitiría la legitimidad de que pusiera en juego su capital en saberes, capital, no en vano, institucionalmente reconocido, y porque, por otro lado, los propios turistas verían acrecentado su propio capital merced a esas informaciones; incremento este que no se reconocería por institución alguna, pero que por vía experencial acercaría al turista al conjunto de agentes que he denominado "no especializados", ya que incremento de capital sería, al fin y al cabo.

En definitiva, una buena parte de las actitudes, conductas, evaluaciones morales y percepciones de los turistas, cuando la "autenticidad" se pone en juego, se explican con más claridad rehuyendo el complejo mundo de los esencialismos (“¿qué es la autenticidad?”) y analizándolas en su interacción dentro de entornos más amplios, del mismo modo que es más fácil saber algo sobre el azufre, digamos, observando sus reacciones en compuestos que escudriñando en su sulfúrica esencia.

Algunas de las dificultades que citaba al principio de estas páginas, como el rango de los discursos nativo y etnográfico, pierden parte de su complejidad cuando el análisis se amplía y perfila las conductas socioculturales puestas en práctica en tiempos y espacios excepcionales dentro de campos de acción ordinarios; cuando se trata de hacer ciencia social en el dominio de la ciencia social y se revelan los mecanismos que subyacen a los fenómenos. Lo que no es ciencia social es plantearse in- 
terrogantes esencialistas folk.

Una ciencia social que otee en las alturas —o sondee en las profundidades- de la metafísica como muestra de su sutileza conceptual (o, por poner otros ejemplos de habilidad en la elusión, trate de afiliarse a alguna cosa genética como sustento último de toda explicación, o procure encontrar en la "mente" los elementos causales de la conducta) soslayará y esquivará fastidiosos problemas epistémicos, sin duda, pero no los eliminará, qué le vamos a hacer. Se habrá limitado a pasarle a cualquier otra voluntariosa disciplina sus propias complicaciones, o, como suele decirse, colocarle el marrón.

\section{Bibliografía}

Augé, Marc

1998 [1992] Los No Lugares, Barcelona: Gedisa.

Banton, M. (comp.)

1999 [1960] Antropología de las sociedades complejas, Madrid: Alianza.

Baudrillard, Jean

2002 [1978]Cultura y simulacro, Barcelona: Kairós.

Berger, $\mathrm{P}$.

1973 "Sincerity and Authenticity in Modern Society", Public Interest, 31.

Boas, Franz

2008 [1889] "Sobre los sonidos alternantes", en Franz

Boas: Textos de Antropología, Madrid: Ed. Universitaria Ramón Areces.

Bourdieu, Pierre

1988 [1979] La distinción. Criterio y bases sociales del gusto, Madrid: Taurus.

Bruner, Edward M.

2005 Culture on Tour, Chicago y Londres: University of Chicago Press.

Díaz De Rada, Ángel

2007 "Valer y valor. Una exhumación de la teoría del valor para reflexionar sobre la desigualdad y la diferencia en relación con la escuela", Revista de Antropología Social, 16.

Francesch, Alfredo

2002 "Oiga, disculpe, pero yo vivía aquí, El Ecologista, $\mathrm{n}^{\circ} 29$.

2004 "Los conceptos del turismo. Una revisión y una respuesta", Gazeta de Antropología, 20, <http:// www. ugr.es/ pwlac/G20_29Alfredo_Francesch.html>.

Geertz, Clifford

2002 [2000] Reflexiones antropologicas sobre temas filosoficos, Barcelona: Paidós.

Gidenns, Anthony

2004 [1984] La constitución de la sociedad. Bases para la teoría de la estructuración, Buenos Aires: Amo- rrortu.

Ginsberg, M.

1934 Sociology, Londres: Butterworth.

Goffman, Irving

2001 [1959] La presentación de la persona en la vida cotidiana, Amorrortu: Buenos Aires.

Handler, Richard

1986 "Authenticity", Anthropology Today, 2, 1.

Handler, Richard y Saxton, William

1988 "Dyssimulation: Reflexivity, Narrative, and the Quest for Authenticity in "Living History"', Cultural Anthropology, 3(3).

Jafari, Jafar

1987 "The Tourist System, Sociocultural Model for Theoretical and Practical Application", Problems of Tourism/Problemy Turystyki.

1988 « Le système du touriste: modèles socio-culturels en vue d'applications théoriques et

pratiques, Loisir et Societé/Society and Leisure, 11 (1).

Maccannell, Dean

1976: The Tourist: A New Theory of the Leisure Class, Nueva York: Schocken Books.

Mayer, Adrian C.

"La importancia de los cuasi grupos en el estudio de las sociedades complejas", en BANTON, M. (comp.), 1999 [1960] Antropología de las sociedades complejas, Madrid: Alianza.

Reisinger, Yvette; Steiner, Carol J.

2006 "Reconceptualizing object authenticity", Annals of Tourism Research, 33(1).

Rodríguez Regueira, José Luis

2000 "Narcisismo y muerte de la alteridad. Universals Port Aventura como escenario de juego y seducción”, Gazeta de Antropología, 16, <http://www.ugr. es/ pwlac/G16_15JoseLuis_Rodriguez_Regueira. html>.

Santana, Agustín

2003 "Patrimonios culturales y turistas: Unos leen lo que otros miran”, Pasos, Revista de Turismo y patrimonio Cultural, 1(1).

Sindiga, Isaac

1999 Tourism and African Development: Change and Challenge of Tourism in Kenya, Leiden: Ashgate.

Steiner, Carol J.; Reisinger, Yvette

2006 "Understanding existential authenticity", Annals of Tourism Research, 33(2).

Velasco, Honorio, Díaz De Rada, Ángel, Cruces, Francisco, Fernández, Roberto, Jiménez De Madariaga, Celeste, Sánchez Molina, Raúl

2006 La sonrisa de la institución. Confianza y riesgo en sistemas expertos, Madrid: Ed. Universitaria Ramón Areces. 
Wang, Ning.

1999 "Rethinking Authenticity in Tourism Experience", Annals of Tourism Research 26(2).

\section{NOTAS}

1. Como recurso estilístico, me permito introducir sin comillas una locución característica de los turistas españoles cuando se refieren a destinos exteriores al llamado Primer Mundo: "este tipo de países".

2. Utilizo grafía del castellano para sonido del área de Talek. Es posible ver la transcripción de la palabra "guerrero" como "muran", "moran", "morani", etc. Inevitable referirse al clásico trabajo de Boas (2008) sobre estas cuestiones de percepción de sonidos poco familiares.

3. Existen, como cabía esperar, modalidades múltiples de artefactos culturales de formas masái, producidos para el consumo turístico. Pueden verse estimables materiales al respecto en Bruner (2005).

4. En este sentido, puede verse Sindiga (1999) y Francesch (2002).

5. Aunque he usado el verbo "ofrecen" en presente, ignoro si las cosas siguen ocurriendo así. Los hechos que presentaré ocurrieron hace ya bastante tiempo.

6. Se entiende por "cuasi-grupo" una entidad "sin una estructura reconocible, pero cuyos miembros tienen en común ciertos intereses o formas de comportamiento que podrían inducirles en cualquier momento a configurarse como grupos definidos" (Ginsberg, 1934, apud Mayer 1999:108). Algo muy aplicable al conjunto de agentes turísticos. Cf. Francesch (2004).

7. El Mundo, 5 de mayo de 1999.

8. "Turistidad" es un término creado por Jafari (1987 y 1988): tourisdom.

9. Por ejemplo, Reisinger y Steiner (2006), Steiner y Reisinger (2006), Santana (2003), Wang (1999), Handler y Saxton (1988), Handler (1986), entre otros.

10. Es cierto que las guías de viaje pueden dar noticia de este tipo de atracciones. Sin embargo, muchos turistas prescinden de usar guías, algo inútiles en los circuitos minuciosamente programados y que cuentan con un guía humano. Además de este factor, hay que considerar que algunas de estas actividades no están abiertas a cualquiera que pase y las pague, sino que se producen ex profeso para la empresa que conduce al grupo.

11. Tal vez, siguiendo a Giddens (2004: 39 y ss.), fuera más adecuado hablar de "fiabilidad" [trust], matizando que esa fiabilidad se deposita en los sistemas expertos y en las señales simbólicas, no en las personas.
La fiabilidad, según este autor, tendría en cuenta las alternativas y la posibilidad de que las cosas pueden no salir bien, mientras que la confianza omite estas contingencias. Ver Velasco et al. (2006).

12. Por los mismos motivos, puramente analíticos, excluiré la agencia puesta en el campo por los actores cuya autenticidad se debate, los danzantes masái en el caso que nos ocupa. La omisión no es un olvido.

13. Con todo, hay una tendencia a la escolarización y certificación de este tipo de saberes, tradicionalmente al margen del mundo escolar.

14. Para el doble papel de etnógrafo al margen del campo y actor en el campo, pero no como etnógrafo, puede verse, una vez más, Bruner (op. cit.)

Recibido:

$12 / 05 / 10$

Reenviado:

$15 / 09 / 10$

Aceptado:

$01 / 12 / 10$

Sometido a evaluación por pares anónimos 